\author{
®Т. К. Мавропуло, І. Ю. Архіпова, К. Ю. Соколова \\ ДЗ «Дніпропетровська медична академія МОЗ Украӥни»
}

\title{
СТАН ЛІКВОРНИХ ПРОСТОРІВ У НЕДОНОШЕНИХ ДІТЕЙ
}

СТАН ЛІКВОРНИХ ПРОСТОРІВ У НЕДОНОШЕНИХ ДІТЕЙ. Ультразвукове дослідження $є$ одним 3 найбільш поширених методів, які використовуються для оцінки стану нервової системи. Існують численні дослідження, які показали діагностичну цінність вимірювання субарахноїдальних просторів у немовлят. Однак інформація про кореляцію між такими ознаками, як календарний вік, гестаційний вік і стан зовнішніх лікворних просторів, $\epsilon$ досить суперечливою. Метою даного дослідження було визначити зв'язок між календарним віком у недоношених дітей різного гестаційного віку і станом зовнішніх лікворних просторів. При проведенні нейросонографічного дослідження вимірювали міжпівкульну щілину в 98 недоношених дітей різного гестаційного віку протягом перших п'яти місяців життя. Отримані дані були проаналізовані за допомогою статистичної програми Statistica 8. Розміри

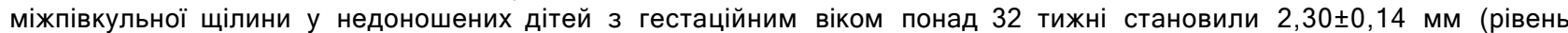

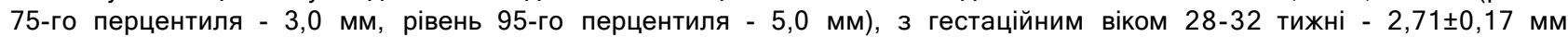
(рівень 75-го перцентиля - 4,0 мм, рівень 95-го перцентиля - 5,5 мм), з гестаційним віком менше 28 тижнів $1,20 \pm 0,11$ мм. Менший гестаційний вік при народженні зумовлював менші розміри зовнішніх лікворних просторів. Систематичний нейросонографічний скринінг для недоношених дітей $є$ необхідним і прийнятним для забезпечення ранньої діагностики, що могло б значно поліпшити проведення реабілітаційних заходів, а також надати більш достовірну прогностичну інформацію.

СОСТОЯНИЕ ЛИКВОРНЫХ ПРОСТОРОВ У НЕДОНОШЕННЫХ ДЕТЕЙ. УЛЬтразвУковое исследование является одним из наиболее распространенных методов, которые используются для оценки состояния нервной системы. Имеются многочисленные исследования, которые показали диагностическую ценность измерения субарахноидальных пространств у новорожденных. Однако информация о корреляции между такими признаками, как календарный возраст, гестационный возраст и состояние внешних ликворных пространств, достаточно противоречива. Целью данного исследования было определить связь между календарным возрастом у недоношенных детей различного гестационного возраста и состоянием внешних ликворных пространств. При проведении нейросонографического исследования измеряли межполушарную щель у 98 недоношенных детей различного гестационного возраста в течение первых пяти месяцев жизни. Полученные данные были проанализированы с помощью статистической программы Statistica 8. Размеры межполушарной щели у

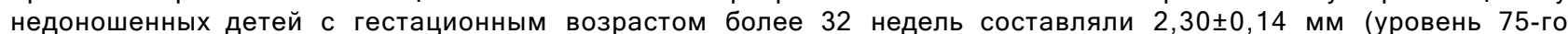

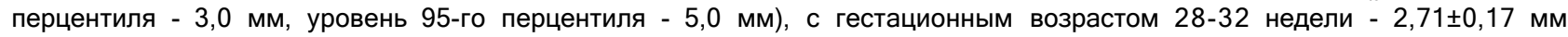
(уровень 75-го перцентиля - 4,0 мм, уровень 95-го перцентиля - 5,5 мм), с гестационным возрастом менее 28

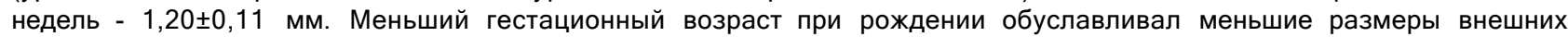
ликворных пространств. Систематический нейросонографический скрининг для недоношенных детей является необходимым и приемлемым для обеспечения ранней диагностики, что могло бы значительно улучшить проведение реабилитационных мероприятий, а также предоставить более достоверную прогностическую информацию.

CONDITION OF CEREBROSPINAL FLUID SPACES IN PREMATURE INFANTS. Ultrasound examination is one of the most common method for assessing the state of the nervous system. Several studies have shown that the method is quite valuable in measuring the subarachnoid spaces in normally developing infants. However, the correlation between such features as calendar age, gestational age and condition of the exterior liquor spaces is controversial. In our study, we sought to determine the relationship between calendar age in premature infants (gestational age was different at birth) and the state of the subarachnoid space. In conducting the study, we missure hemispheric slit in 98 premature infants of different gestational age in the first five months of life. The obtained data have been analyzed with Statistica 8 software. Dimensions of hemispheric slit in preterm infants with gestational age over 32 weeks $-2.30 \pm 0.14 \mathrm{~mm}$ (level 75 th percentile - $3.0 \mathrm{~mm}$ level 95th percentile $-5.0 \mathrm{~mm}$ ), with a gestational age of $28-32$ weeks $-2.71 \pm 0,17 \mathrm{~mm}$ (level 75th percentile - $4.0 \mathrm{~mm}$ level 95th percentile $-5.5 \mathrm{~mm}$ ) with gestational age less than 28 weeks $-1.20 \pm 0.11 \mathrm{~mm}$. The smaller was the gestational age at birth, the smaller outdoor cerebrospinal fluid spaces. Systematic neurosonographic screening for preterm infants is necessary and appropriate to ensure early diagnosis, which could greatly improve the rehabilitation measures as well as to provide more accurate prognostic information.

Ключові слова: недоношені діти, ультразвукове дослідження, міжпівкульна щілина.

Ключевые слова: недоношенные дети, ультразвуковое исследование, межполушарная щель.

Key words: premature infants, ultrasound examination, interhemispheric slit.

ВСТУП. Мозок недоношеної дитини вразливий як до геморагічних, так і до ішемічних ушкоджень, що пов'язано із судинними, клітинними й анатомічними особливостями, а також з численними періодами фізіологічної нестабільності, які призводять до пору- шень мозкового кровотоку [1-3]. Розширення зовнішніх лікворних просторів (ЗЛП) (субарахноїдальних просторів та міжпівкульної щілини) є частою ультразвуковою знахідкою при скринуючих обстеженнях дітей першого року життя [4, 5]. Дослідження по- 


\section{Педіатрія}

казали, що динамічне вимірювання зовнішніхлікворних просторів може мати навіть більшу діагностичну значущість відносно нормального розвитку мозку, ніж динаміка росту окружності голови. Це зумовлює актуальність дослідження ліквородинамічних змін у дітей першого року життя [8, 12].

Проблема визначення нормальних показників вимірювання розмірів субарахноїдальних просторів та міжпівкульної щілини широко дискутується останні два десятиліття [5-8]. Літературні дані щодо нормативних показників різняться. Верхню межу нормального розміру міжпівкульної щілини вказують у діапазоні від 6,0 до 8,5 мм [8, 13-17]. Згідно з іншими даними, середні значення розміру міжпівкульної щілини - 2,8 мм, рівень 95-го процентиля - 6 мм, без достовірної кореляції між віком і шириною субарахноїдальних просторів [6]. Вказують і на менші значення нормативних показників. Встановлено, що ширина нормальних субарахноїдальних просторів збільшується 3 народження приблизно до 7 місяців життя, після чого між 1 і 2 роками спостерігається поступове зменшення розмірів [16, 17].

Розширення зовнішніх лікворних просторів (неатрофічного характеру) часто описується в літературі як «зовнішня гідроцефалія», «екстравентрикулярна обструктивна гідроцефалія», «ідіопатична/доброякісна гідроцефалія», «розширення субарахноїдального простору» [5] і визначається як швидкий приріст окружності голови у немовлят в поєднанні зі збільшеними субарахноїдальними просторами, відсутністю або помірним розширенням шлуночків мозку та відсутністю «клінічних ознак підвищеного внутрішньочерепного тиску» $[5,8]$.

Висловлена думка, що широкі ЗЛП можуть бути варіантом норми у дітей першого року життя [9-11]. Проте $\epsilon$ кілька генетичних захворювань, при яких розширення ЗЛП може бути ранньою ознакою патології (деяких видів краніосиностозів, ахондроплазії, синдрому Sotos, глутаровоїацидуріїтипу 1). Наявність розширення ЗЛП може викликати підозру на існування субдуральної гематоми [2-5, 13, 14].

Клінічними проявами розширення ЗЛП може бути транзиторна або постійна затримка психомоторного розвитку (близько чверті дітей демонстрували відхилення розвитку при проведенні Денверського оцінювального тесту) [5, 18]. Розширення екстрацеребрального простору та міжпівкульної щілини у недоношених дітей може бути проявом атрофічних процесів [3]. Відомий факт зв'язку негрубих структурних змін мозкової тканини, діагностованих при ультразвуковому обстеженні (до яких і належить розширення зовнішніх ліквороутримуючих просторів), з наступними проявами синдрому мінімальної мозкової дисфункції [15, 20].

До транзиторного розширення ЗЛП призводить відстрочене дозрівання ворсинок павутинної оболонки, не здатних до поглинання ліквору (він накопичується і розширює субарахноїдальний простір та шлуночки всередині податливого черепа немовляти, таким чином попереджуючи помітне збільшення внутрішньочерепного тиску). Інші теорії - створення одностороннього клапана павутинної оболонки (ліквор «розділяється на смужки»), більш швидкий ріст черепа, ніж мозку (забезпечення транзиторного субарахноїдального накопичення ліквору), перешкоджання реабсорбції ліквору субдуральною рідиною, виражене збільшення вироблення спинномозкової рідини протягом першого року життя, зміни артеріального та венозного кровотоку і зміна тиску венозних синусів [4, 5, 19].

Динамічне визначення стану зовнішніх лікворних просторів проводилось, головним чином, у доношених дітей. Метою $ж$ нашої роботи було дослідження стану ЗЛП у недоношених дітей різного гестаційного віку.

МАТЕРІАЛИ ТА МЕТОДИ. ГрУпУ спостереження становили 98 дітей першого року життя, які народилися до закінчення повних 37 тижнів вагітності. 56 малюків мали гестаційний вік при народженні 2832 тижні, 5 - менше 28 тижнів. Вибір такого вікового розподілу недоношених малюків був зумовлений тим, що до досягнення гестаційного віку 32 тижні відмічається значна незрілість структур стінки внутрішньомозкових судин у кількісному та якісному відношеннях. Групу порівняння склали 324 доношених малюки відповідного віку 3 клінічними ознаками нетяжких («переважно функціональних») гіпоксичних уражень ЦНС. 3 груп спостереження були виключені діти, які мали ознаки деструктивних ушкоджень мозкової тканини та прогресуючої внутрішньої гідроцефалії, а також малюки, які отримували на момент обстеження медикаментозне лікування.

Ультразвукове обстеження мозку проводилось згідно з уніфікованою методикою за допомогою ультразвукових пристроїв з мікроконвексними датчиками частотою 10, 7,5 та 5,0 Мгц. Вимірювали розміри міжпівкульної щілини в передніх (МПщП), середніх (МПщС) та задніх (МПщЗ) відділах, відповідно, в стандартних коронарних зображеннях через лобні частки мозку, через третій шлуночок, через потиличну частку.

Клінічне та сонографічне обстеження проводили протягом перших п'яти місяців життя. Було обстежено повторно 41 дитину.

Для статистичної обробки отриманих даних використовувалися метод визначення вірогідних кореляційних зв'язків (метод кореляційного аналізу Спірмена), аналіз значущості відмінностей між групами для вибірок з невідомим розподілом (медіанний тест, Н-критерій Краскела-Уолліса).

РЕЗУЛЬТАТИ ДОСЛІДЖЕННЯ ТАЇХ ОБГОВОРЕНня. Результати вимірювання розмірів міжпівкульної щілини у дітей різного гестаційного та календарного віку наведено в таблиці 1 .

Середні розміри міжпівкульної щілини у доношених дітей протягом періоду спостереження становили 3,16 $\pm 0,07$ мм (рівень 75-го перцентиля - 4,0 мм, рівень 95-го перцентиля - 7,0 мм), у недоношених

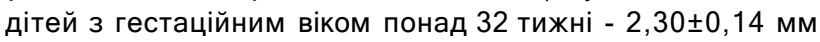
(рівень 75-го перцентиля - 3,0 мм, рівень 95-го перцентиля - 5,0 мм), з гестаційним віком 28-32 тижні -

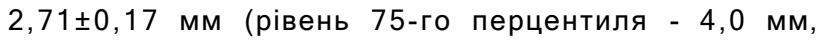
рівень 95-го перцентиля - 5,5 мм), 3 гестаційним

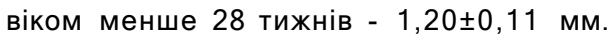




\section{Педіатрія}

Таблиця 1. Сонографічні показники дітей різних вікових груп з різним гестаційним віком (ГВ) при народженні $(M \pm T)$

\begin{tabular}{|c|c|c|c|c|c|}
\hline \multirow{3}{*}{ 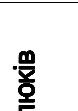 } & \multirow{2}{*}{ Календарний вік, міс. } & \multirow{2}{*}{ ГВ, тиж. } & \multicolumn{3}{|c|}{ Показник } \\
\hline & & & МПЩП, мм & МПЩС, мМ & МПЩЗ, мм \\
\hline & \multirow[t]{4}{*}{ діти місячного віку з ГВ } & до 28 & $1,50+0,50$ & $1,50+0,50$ & $1,50+0,50$ \\
\hline \multirow{5}{*}{ 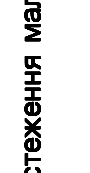 } & & $28-32$ & $2,06+1,19$ & $1,97 \pm 0,16$ & $2,07 \pm 0,19$ \\
\hline & & $33-36$ & $1,74 \pm 0,18$ & $1,55+0,11$ & $2,05+0,22$ \\
\hline & & $37-42$ & $2,24 \pm 0,10$ & $2,49+0,10^{*}$ & $2,41 \pm 0,10$ \\
\hline & \multirow[t]{4}{*}{ діти двомісячного віку 3 ГВ } & до 28 & $1,50+0,29$ & $1,50+0,29$ & $1,50+0,29$ \\
\hline & & $28-32$ & $1,91+0,24$ & $2,27 \pm 0,33$ & $2,50+0,34$ \\
\hline \multirow{7}{*}{ 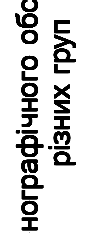 } & & $33-36$ & $3,00+0,34$ & $2,67 \pm 0,33$ & $3,33+0,71$ \\
\hline & & $37-42$ & $2,49+0,11$ & $2,24 \pm 0,10$ & $2,41 \pm 0,10$ \\
\hline & \multirow[t]{4}{*}{ діти тримісячного віку 3 ГВ } & до 28 & $1,15+0,00$ & $1,15+0,00$ & $1,15+0,00$ \\
\hline & & $28-32$ & $3,40+0,42$ & $3,50+0,40$ & $3,50+0,51$ \\
\hline & & $33-36$ & $3,90+0,55$ & $3,52 \pm 1,31$ & $3,40+1,19$ \\
\hline & & $37-42$ & $4,24 \pm 0,19$ & $3,71 \pm 0,17$ & $3,50+0,17$ \\
\hline & \multirow[t]{4}{*}{ діти чотиримісячного віку 3 ГВ } & до 28 & $1,00+0,00$ & $1,00+0,00$ & $1,00+0,00$ \\
\hline ᄒํㅇ & & $28-32$ & $4,00+0,42$ & $4,00+0,45$ & $3,93+0,39$ \\
\hline \multirow{6}{*}{ 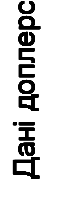 } & & $33-36$ & $3,17 \pm 1,92$ & $2,83+1,59$ & $4,00+2,08$ \\
\hline & & $37-42$ & $4,51+0,23$ & $3,93+0,21$ & $3,79 \pm 0,21$ \\
\hline & \multirow[t]{4}{*}{ діти п'ятимісячного віку 3 ГВ } & до 28 & $1,00+0,00$ & $1,00+0,00$ & $1,00+0,00$ \\
\hline & & $28-32$ & $3,63+0,47$ & $2,38+0,24$ & $2,63+0,24$ \\
\hline & & $33-36$ & $3,95+0,46$ & $2,42 \pm 0,22$ & $2,58+0,22$ \\
\hline & & $37-42$ & $4,53+0,29$ & $3,92 \pm 0,28$ & $3,92 \pm 0,26$ \\
\hline
\end{tabular}

Примітка. Рівень значущості відмінностей між групами р<0,05 (критерій Краскела-Уолліса, медіанний тест).

Достовірні відмінності показників вимірювання груп дітей з різним гестаційним віком були зафіксовані лише наприкінці першого місяця життя і в подальшому не виявлялись, що, можливо, було зумовлено невеликою кількістю дітей у групах з малим гестаційним віком.

Протягом перших п'яти місяців життя в загальній групі спостереження вищий гестаційний вік при народженні корелював 3 більшими розмірами міжпівкульної щілини $(\mathrm{R}=0,192, \mathrm{p}<0,05)$. Подібна залежність виявлялась у групі недоношених малюків $(R=0,169, p<0,05)$ і не виявлялась у групі доношених дітей. Розширення міжпівкульної щілини неатрофічного характеру можна вважати ознакою «дозрівання» структур головного мозку.

Водночас були виявлені достовірні відмінності розмірів міжпівкульної щілини (підрахування медіанного тесту, критерію Краскела-Уолліса) в групах дітей різного гестаційного віку залежно від календарного віку. В групі доношених дітей $p=0,000$ (достовірність відмінностей розмірів міжпівкульної щілини у дітей різного календарного віку), в недоношених дітей 3 гестаційним віком понад 32 тижні $p=0,020$. Але такі відмінності (розбіжності вікових даних вимірювання міжпівкульної щілини або наявність вікового приросту протягом п'яти місяців життя) не були встановлені для недоношених дітей з гестаційним віком 28 32 тижні $(p=0,120)$ та дітей 3 гестаційним віком менше 28 тижнів $(p=0,995)$.

Були виявлені достовірні кореляційні зв'язки між розмірами міжпівкульної щілини у недоношених дітей та клінічними ознаками неврологічної дисфункції: збіжна косоокість $(R=0,093)$, спонтанний рефлекс Mopo $(R=-0,095)$, зміни м'язового тонусу $(R=0,077)$, судоми в анамнезі $(R=0,066)$, помірна затримка психомоторного розвитку $(R=0,144)$.

Таким чином, менший гестаційний вік при народженні зумовлював менші розміри зовнішніх лікворних просторів (міжпівкульної щілини), що, можливо, $\epsilon$ «віддзеркаленням» активності дозрівання структур мозку. Були виявлені достовірні кореляційні зв'язки між розмірами міжпівкульної щілини у недоношених дітей та клінічними ознаками неврологічної дисфункції. Слід зважати на різні дані щодо показників норми для дітей різного гестаційного віку: в доношених дітей рівень 75-го перцентиля - 4,0 мм, рівень 95-го перцентиля - 7,0 мм, у недоношених дітей 3 гестаційним віком понад 32 тижні рівень 75-го перцентиля - 3,0 мм, рівень 95-го перцентиля - 5,0 мм.

При цьому діти першого року життя з гестаційним віком при народженні 32 тижні та менше не демонстрували ознак достовірних змін розмірів міжпівкульної щілини протягом перших п'яти місяців життя. Тож визначення «фізіологічної норми» стану зовнішніх лікворних просторів для таких недоношених немовлят повинно бути іншим.

ВИСНОВКИ. Зважаючи нате, що були виявлені достовірні кореляційні зв'язки між розмірами міжпівкульної щілини у недоношених дітей та клінічними ознаками неврологічної дисфункції, систематичний нейросонографічний скринінг для недоношених дітей $є$ необхідним і прийнятним для забезпечення ранньої діагностики.

ПЕРСПЕКТИВИ ПОДАЛЬШИХ ДОСЛІДЖЕНЬ. Необхідні дослідження діагностичного значення ліквородинамічних порушень як критерію субоптимального нервово-психічного розвитку та порушень поведінки у недоношених дітей, народжених з дуже малою та екстремально малою масою тіла. 


\section{Педіатрія}

\section{СПИСОК ЛІТЕРАТУРИ}

1. Rutherford M. A. MRI of the Neonatal Brain, http:// www.mrineonatalbrain.com/ index.php 2002-2015.

2. Early prediction of neurological outcome by term neurological examination and cranial ultrasound in very preterm infants / P. Amess, C. McFerran, Y. Khan, H. Rabe // Acta Paediatr. - 2009. - Vol. 98. - P. 448-453.

3. Sauve R. Routine screening cranial ultrasound examinations for the prediction of long term neurodevelopmental outcomes in preterm infants / R. Sauve // Paediatr. Child Health. - 2001. - Vol. 6(1). - P. 39-43.

4. Paciorkowski A. R.When Is Enlargement of the Subarachnoid Spaces Not Benign? A Genetic Perspective / A. R. Paciorkowski, R. M. Greenstein // Pediatric Neurology - 2007. - Vol. 37 (Issue 1) - P. 1-7.

5. Benign external hydrocephalus: a review, with emphasis on management / S. M. Zahl, A. Egge, E. Helseth [et al.] // Neurosurg. Rev. - 2011. - Vol. 34. - P. 417. 432.

6. Libicher M. US measurement of the sub-arachnoid space in infants: normal values / M. Libicher, J. Truger / / Radiology. - 1992. - Vol. 184. - P. 749-751.

7. Frankel D. A. High resolutionsonographic determination of the normal dimensions ofthe intracranial extraaxial compartment in the newborninfant / D. A. Frankel, D. P. Fessell, W. P. Wolfson // J. Ultrasound Med. - 1998. - Vol. 17. - P. 411-415.

8. A novel index in healthy infants and children subarachnoid space: ventricle ratio / A. Okur, O. Kucuk, S. Karacavus [et al.] // Folia Morphol. - 2013. - Vol. 72 (2). - P. 142-146.

9. Developmental changes in normal cranial measurements by com-puted tomography / Y. Fukuyama, M. Miyao, T. Ishizu, H. Maruyama // Dev. Med. Child. Neurol. - 1979. - Vol. 21. - P. 425-432.

10. Pedersen $H$. Measurement of the normal ventricular system and supratentorial subarachnoid space in children with computed tomography. / H. Pedersen, M. Gyldensted, C. Gyldensted // Neuroradiology. - 1979. Vol. 17. - P. 231-237.

11. External hydrocephalus: radiologic spectrum and differentia-tion from cerebral atrophy / J. Maytal, L. A. Alvarez, C. M. Elkin, S. Shinnar//Am. J. Roentgenol. - 1987. - Vol. 148. - P. 1223-1230.

12. Measurement of the subarachnoid space by ultrasoundin preterm infants / D. L. Armstrong, C. Bagnall, J. E. Harding, R. L. Teele // Arch. Dis. Child. Fetal. Neonatal. Ed. - 2002. - Vol. 86. - P. 124-126.

13. Subdural hematomas in infants with benign enlargement of the subarachnoid spaces are not pathognomonic for child abuse / P. D. McNeely, J. D. Atkinson, G. Saigal [et al.] // AJNR Am. J. Neuroradiol. - 2006. - Vol. 27. - P. 1725-1728.

14. Prevalence of Subdural Collections in Children with Macrocrania / M. V. Greinera, T. J. Richardsb, M. M. Careb, J. L. Leachb // AJNR. - 2013. - Vol. 34. - P. 2373-2378.

15. Барашнев Ю. И. Перинатальная неврология / Ю. И. Барашнев. - М. : Триада-Х, 2001. - 640 с.

16. Ultrasonographic measurement of subarachnoid space and frontal horn width in healthy iranian infants iran / S. Sabouri, A. Khatami, M. Shahnazi [et al.] // J. Child Neurology. - 2011. - Vol. 5 (1). - P. 9-14.

17. Ultrasonographic measurement of subarachnoid space in normal infants and children / W. W. Lam, V. H. Ai, V. Wong, L. L. Leong // Pediatr. Neurol. - 2001. Vol. 25(5). - P. 380-384.

18. Nogueira G. J. Hypodense extracerebral images on computed tomography in children. "External hydrocephalus": a misnomer? / G. J. Nogueira, H. F. Zaglul // Childs Nerv. Syst. - 1991. - Vol. 7. - P. 336-341.

19. Gravendeel J. Cerebral biometry at birth and at 4 and 8 months of age. A prospective study using US / J. Gravendeel, K. Rosendahl // Pediatric Radiology. 2010. - Vol. 40 (10). - P. 1651-1656.

20. Мартынюк В. Ю. Клиническая нейросонография в диагностике нарушений ликвородинамики у детей раннего возраста / В. Ю. Мартынюк, Е. А. Макарова // Нові технології в наданні медичної допомоги новонародженим : матеріали спільної українськопольської наук.-практ. конф. неонатологів. - К., 2000. - C. 79-83. 